\section{Advanced bilateral breast cancer, stage T4c N3 M1}

Poras Chaudhary, Hemant Khowal

Lady Hardinge Medical College and

Associated Dr. Ram Manohar Lohia

Hospital, New Delhi, India

\section{Abstract}

The present study reports a case of advanced bilateral breast cancer with distant metastasis of 4 years for which the patient did not seek any medical advice. The aim of reporting this case is to highlight the fact that such advanced cases are still seen in developing countries.

\section{Introduction}

A 40-year-old lady had bilateral breast lump of 4 years over right side and 3 years over left side, involving almost the entire breast on both sides, for which she did not consult any clinician. She then developed multiple ulceration and nodules over right breast followed by left breast with complete distortion of nipple areola complex over right side followed by development of similar nodules over anterior abdomen (Figure 1).

\section{Case Report}

Breast biopsy was suggestive of invasive ductal carcinoma, estrogen and progesterone receptors were negative and Her-2-neu was also negative, and biopsy from abdominal wall nodules was suggestive of metastatic deposits. Imaging revealed metastasis to lungs and lumbar spine. This was a case of bilateral breast carcinoma, stage T4c N3 M1, and the prognosis is poor in such a case..$^{1,2}$ Chemo and radiotherapy with toilet mastectomy were the only option. ${ }^{1,2}$ Bilateral toilet mastectomy was done and the patient received 3 cycles of chemotherapy (FEC regime - 5-fluorouracil, epirubicin, and cyclophosphamide). After completion of 6 cycles of chemotherapy, the patient was reassessed and radiotherapy was given to the bony metastasis. A written consent for publishing her case was obtained from the patient.

\section{Discussion}

It is not rare to see such locally advanced inoperable breast cancers with multiple distant metastases in many developing countries such as India. Breast cancer accounts for 19$34 \%$ of all cancer cases among women in India and carries a high mortality due to presentation at late stage of the disease. The reason for this kind of scenario is lack of awareness and non-existent breast cancer screening programs. ${ }^{3}$ Somdatta et al. ${ }^{3}$ concluded that awareness about breast cancer is low amongst women even in urban community and there is a need for awareness generation programs. Awareness regarding breast self examination among young generations is useful and it is the most important viable tool for early detection. ${ }^{4}$ Gupta $^{5}$ concluded that health education programs through various channels are needed to increase the awareness and knowledge about breast self examination.

\section{Conclusions}

In underdeveloped and developing coun-

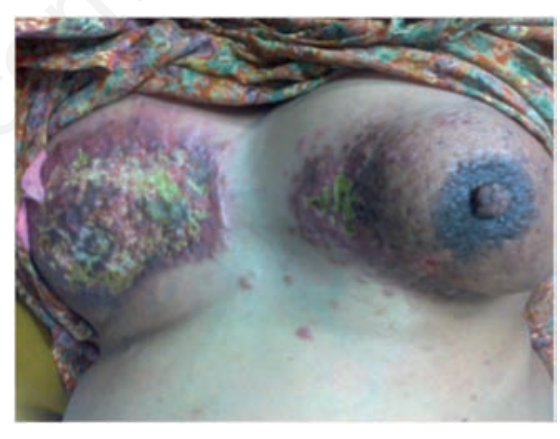

Figure 1. Ulceration over bilateral breast with distortion of nipple areola complex over right side and nodules over anterior abdominal wall.
Correspondence: Poras Chaudhary, Lady Hardinge Medical College and Associated Dr Ram Manohar Lohia Hospital, Baba Kharak Singh Marg, New Delhi 110001, India.

Tel./Fax: +91.9891.4473.358.

E-mail: drporaschaudhary@yahoo.com

Key words: bilateral breast cancer, toilet mastec tomy, India.

Received for publication: 23 November 2013.

Revision received: 31 January 2014

Accepted for publication: 2 July 2014.

This work is licensed under a Creative Commons Attribution 3.0 License (by-nc 3.0).

(C) Copyright P. Chaudhary and H. Khowal 2014 Licensee PAGEPress, Italy

Healthcare in Low-resource Settings 2014; 2:2151 doi:10.4081/hls.2014.2151

tries, there is a need for awareness generation programs to educate about breast cancer to decrease mortality due to this common cancer.

\section{References}

1. Novoa VA. Toilet mastectomy: palliative treatment in women with advanced breast cancer. Ginecol Obstet Mex 2002;70:392-7.

2. Russell RCG, Norman SW, Christopher JKB. Bailey and love's short practice of surgery. London, UK: CRC Press; 2004.

3. Somdatta P, Baridalyne N. Awareness of breast cancer in women of an urban resettlement colony. Indian J Cancer 2008;45: 149-53.

4. Shalini, Varghese D, Nayak M. Awareness and impact of education on breast self examination among college going girls. Indian J Palliat Care 2011;17:150-4.

5. Gupta SK. Impact of health education intervention program regarding breast self examination by women in a semi-urban area of Madhya Pradesh, India. Asian Pac J Cancer P 2009;10:113-7. 